\title{
The effect of topical triturate glyceryl in the treatment of tennis elbow: a randomized clinical trial
}

\author{
Shahla Abolghasemi ${ }^{1}$, Mohammad Hadi Niknegad ${ }^{2}$ Hesam Adin Atashi ${ }^{3}$, Hamid Zaferani Arani ${ }^{3}$ \\ ${ }^{1}$ Assistant Professor, Department of Rheumatology, Tehran Medical Sciences, Islamic Azad University, Tehran, Iran \\ ${ }^{2}$ General Practitioner, Tehran Medical Sciences, Islamic Azad University, Tehran, Iran \\ ${ }^{3}$ Medical Student, Young Researchers and Elite Club, Tehran Medical Sciences, Islamic Azad University, Tehran, Iran
}

\begin{abstract}
Background: Tennis elbow (TE), as a lateral epicondylitis (LE), is a chronic inflammatory and degenerative tendon disease that causes pain in the outer part of the elbow. This study aimed to evaluate the efficacy of topical Trinitrate Glyceryl (GTN) in the treatment of patients with TE.

Materials and methods: In this double-blind clinical trial, 90 patients with TE, referred to Orthopedic and Rheumatology Clinics of Bou-Ali Hospital in Tehran from October 2012 until January 2014, have been studied. They were randomly divided into 2 groups of 45 subjects (treatment and control group). Intervention group received dermal patches and GTN-containing drop, and the control group received dermal patches and liquid paraffin-containing drop (placebo).

Results: Significant improvement in pain and tenderness was observed after 2, 4 and 6 weeks in intervention group compared to control group $(\mathrm{p}<0.05)$.

Conclusion: Based on the findings of this study, GTN has a significant effect on pain relief and tenderness in patients with TE.

Keywords: Tennis elbow, Lateral epicondylitis, Trinitrate glyceryl, Placebo, Pain, Tenderness.

Cited as: Abolghasemi Sh, Niknegad MH, Atashi HA, Zaferani Arani H. The effect of topical triturate glyceryl in the treatment of tennis elbow: a randomized clinical trial. Medical Science Journal of Islamic Azad University, Tehran Medical Branch 2020; 30(2): 167-173.
\end{abstract}

Correspondence to: Hamid Zaferani Arani

Tel: +982122006606

E-mail: hamid_zaferani@iautmu.ac.ir

ORCID ID: 0000-0001-6790-5910

Received: 1 Sep 2019; Accepted: 21 Jun 2020 
مجله علوم يزشكى دانشَاه آزاد اسلامى

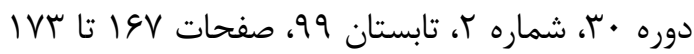

$\overline{\text { Original }}$

Article

\section{تاثير كَليسريل ترى نيترات موضعى در درمان آرنج تنيس بازان: يك مطالعه كار آزمايى بالينى}

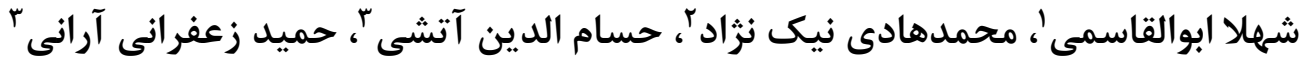

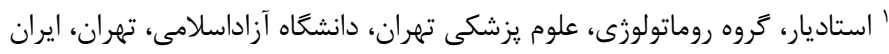

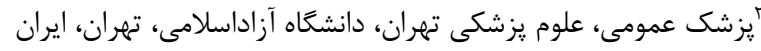

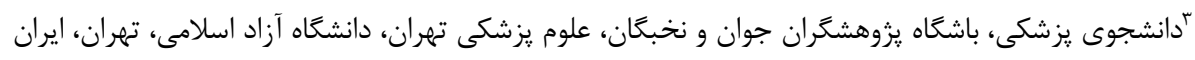

جـكيده

سابقه و هدف: /بيكونديليت جانبى (LE) يا آرنج تنيس بازان (TE) باعث درد در قسمت خارجى آرنج مىشود. در /ين مطالعه نتايج

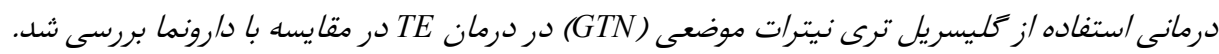

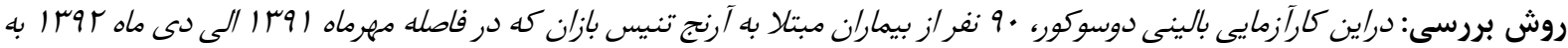

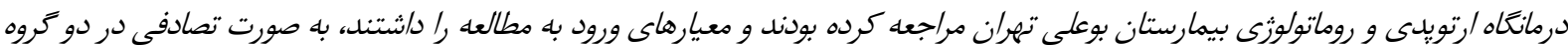

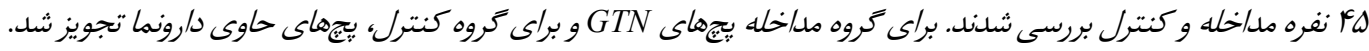

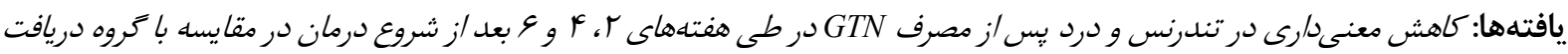

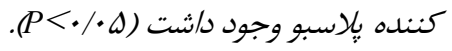
نتيجه كيرى: تجويز NO به طور مستقيم بر روى ناحيه تاندونوياتى به صورت موضعى (GTN) مى ملواند باعث كاهش درد و ساير علايم بيمارى مزمن وازَكان كليدى: بيكونديليت جانبى، بيمارى آرنج تنيس بازان، اكسيد نيتريك، تليسريل ترى نيترات موضعى، دارونما، تندرنس.

مىافتد و با افزايش سن و زمان صرف شـده بـراى انجـام كارهـاى

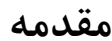

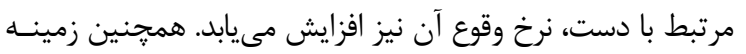

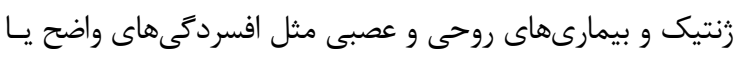

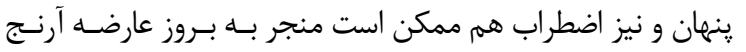

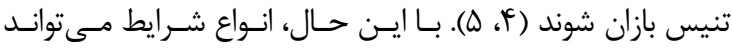

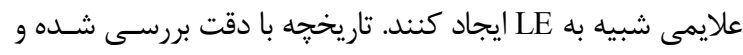
معاينه كامل جسمى، اغلب براى تشخيص اوليه قابل قبـول اسـت.

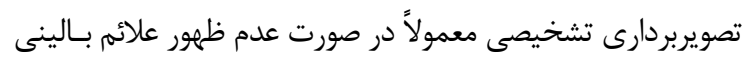

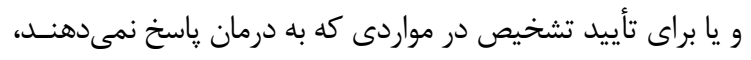

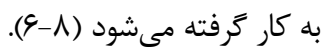

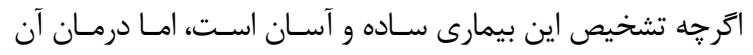

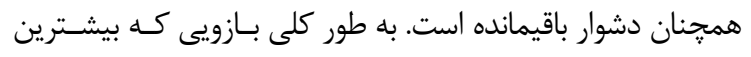

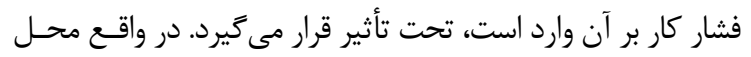

إيكونديليت جانبى (LE)، كه به آن آرنج تنسيس بـازان (TE) نيـز

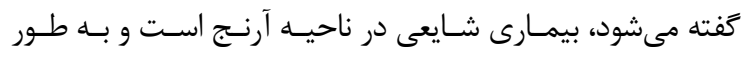

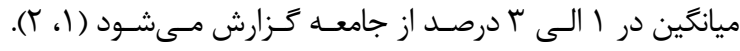

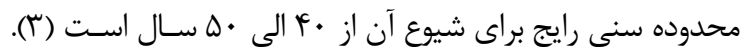

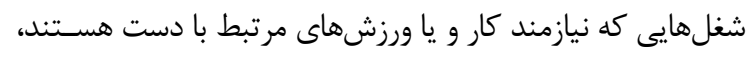

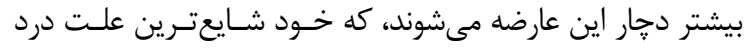
جانبى آرنج است. شيوع اين عارضه در زنان بيشتر از مردان اتفـاق

آدرس نويسنده مسئول: تهران، دانشكاه علوم يزشكى آزاد اسلامى تهران، دانشكده يزشكى، حميد زعفرانى (email: hamid_zaferani@iautmu.ac.ir) آرنى ORCID ID: 0000-0001-6790-5910 تاريخ دريافت مقاله: • • تاريخ هذيرش مقاله: - تاريخ دريافت مقاله 


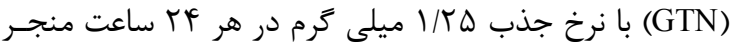

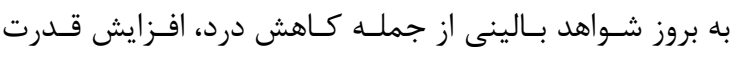

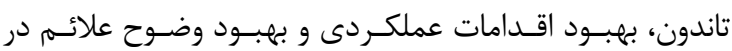

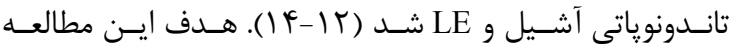
بررسى تأثير استفاده و كـاربرد GTN در تسكين استين درد و بهبـود

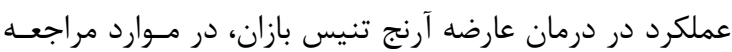
كننده به بيمارستان بوعلى تهران بود.

\section{مواد و روشها}

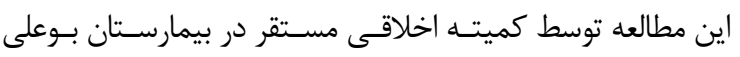

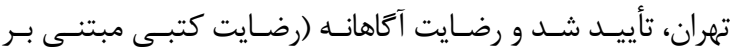

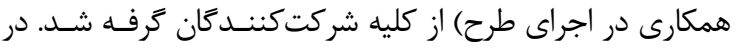

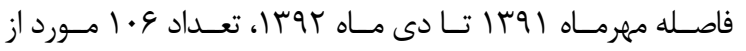

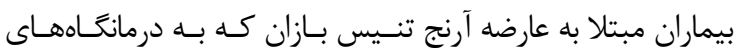

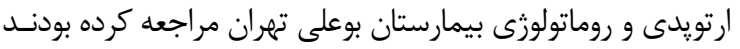

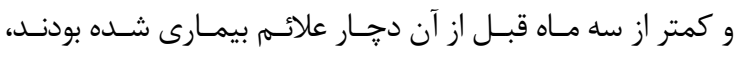

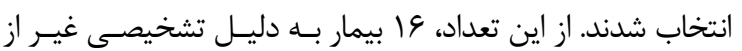

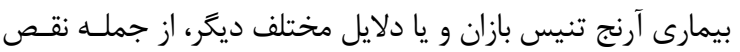

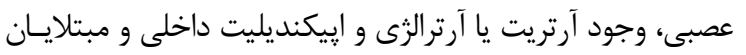

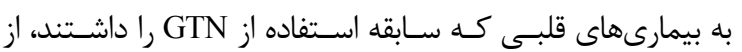

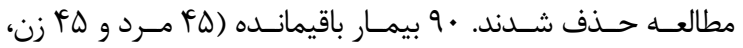

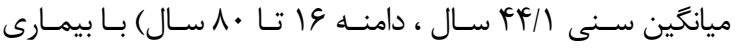

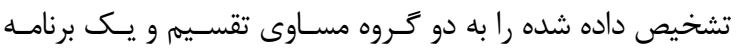

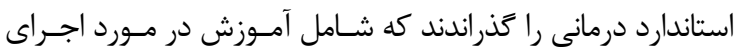
طرح براى بيماران نيز مىشد. معيارهاى ورود به مطالعه بــه شـرح

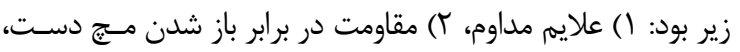

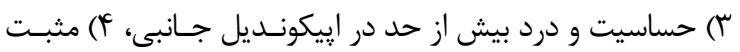

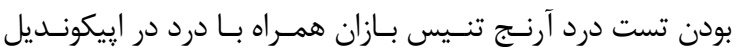

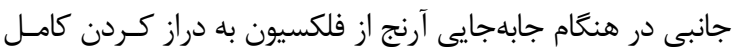

در بررسى حاضر كه به شيوه تصادفى سـاده صـورت گرفـت، ابتـدا

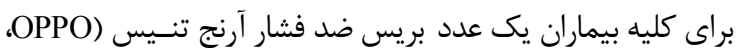

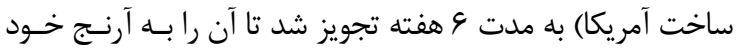

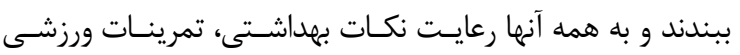
متناسب و عدم استفاده از دست مبتلا توصيه شد. سيس بيمـاران توسط يروهشكَر در دو گروه الـف و ب وارد مطالعـه شــند. بـدين

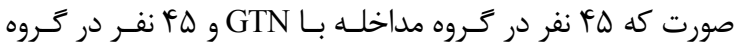

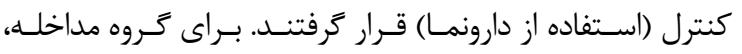

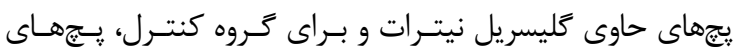

درد روى برجستخى انتهاى استخوان بازو در سـمت بيرونسى آرنسج

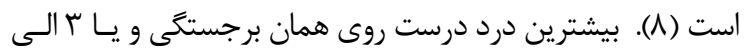

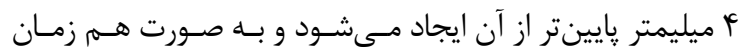

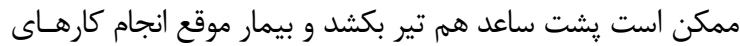

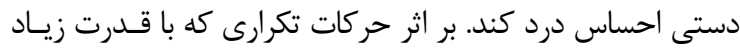

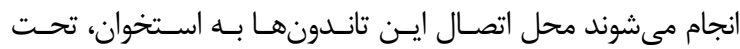

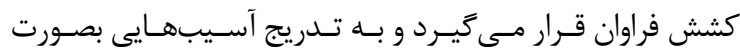
ياركىهاى ميكروسكويى، ريش ريش شدن و تغييـر قـوام تانسدون

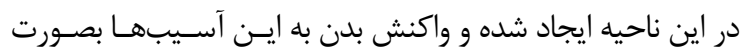

التهاب و درد ظاهر مىشود (9).

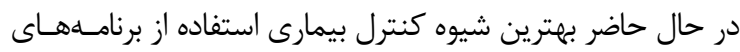

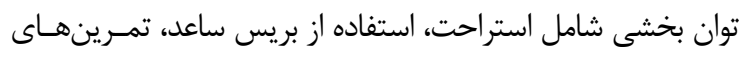
كششى و تقويتى است ( (|، • ()، در حـالى كـهـ متـدهاى ديخــى همجون مصرف NSAID بـه عنـوان خـط اول درمـان بسـيارى از بيمارىهاى تاندونى از جمله درد نيمه خارجى آرنـج رايـج اسـت. NSAID

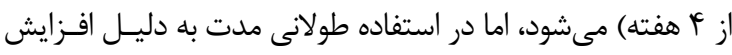

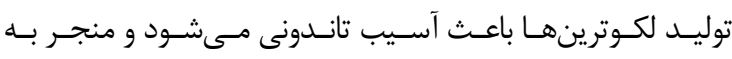

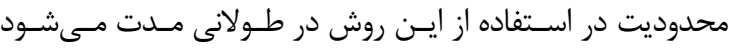

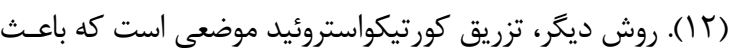

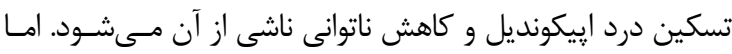

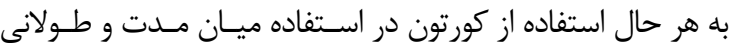
مدت (بـيش از 9 هفتـهـ) داراى عـوارض بسـيارى اسـت (1 (1). در نهايت گزينههاى مختلف جراحى نيز مطرح مىشود كه همخَى در

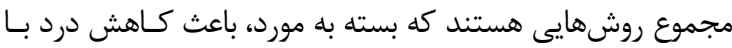

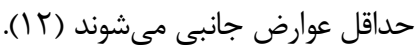
با توجه به وجود عوارض جانبى در روشهاى درمانى دانى ذكر شده،

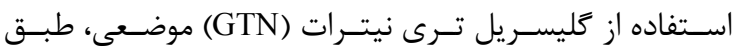
مكانيسم اثرى كه دارد مىتواند نقـش مهمسى در درمـان ايسن

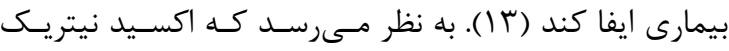
(NO) نيتريك نقش مهمى در ســنتز كـلازن و تـرميم تانـدون دارد و

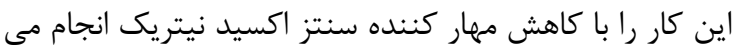

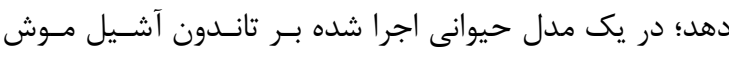
صحرايى، مهار سنتز NO منجر به كاهش سطح مقطـع و بـروز

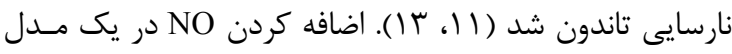

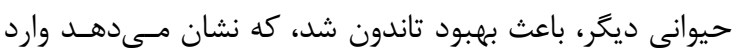

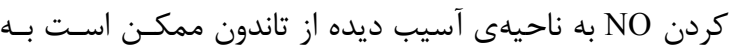
بهبودى آن كمك كند (Y l ( ). در تاندونوياتىهاى مزمن، درمـان با استفاده از NO بــه شـكل كليسـريل موضـعى تـرى نيتـرات 


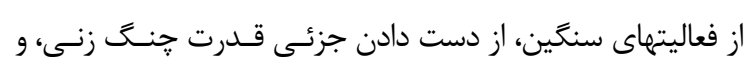

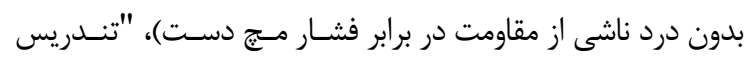

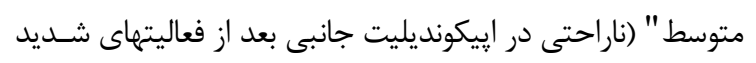
اما با تحمل بيشترى نسبت به قبل از درمان، بيمار راضى يا نســبتا

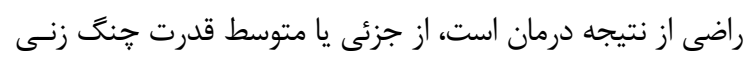

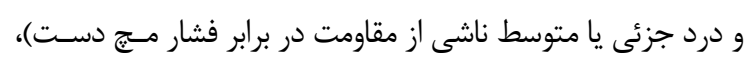

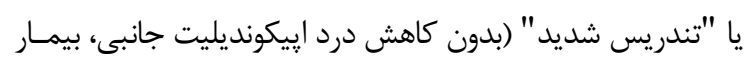

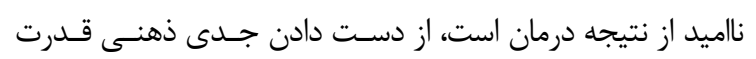

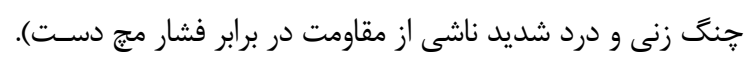

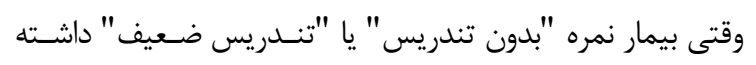

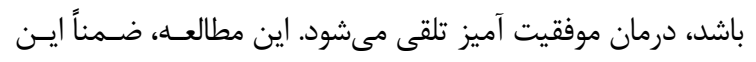

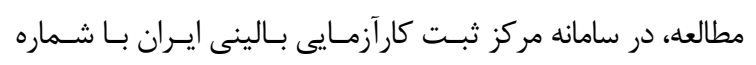
IRCT2015021421075N1

يس از جمع آورى اطلاعـات بـا اسـتفاده از نـرم افـزار آمـارى 19 SPSS

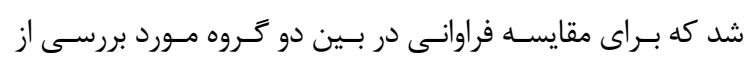

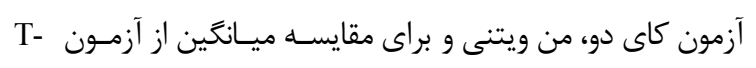

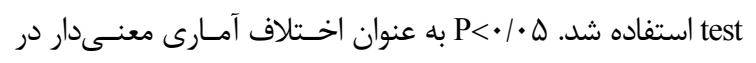
نظر گرفته شد.

\section{بافتهها}

در اين مطالعه ·9 بيمار با ميانگين سنى

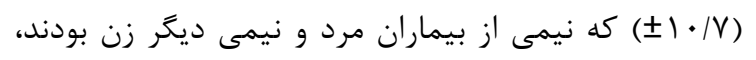
مورد بررسى قرار گرفتند. مشخصات دموَرافيكى بيماران

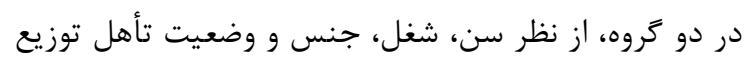

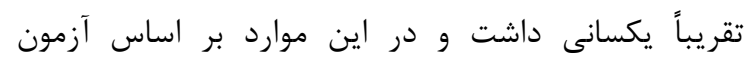

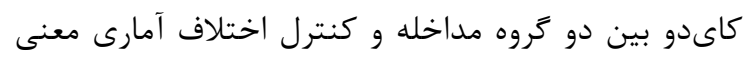

$$
\text { دارى مشاهده نشد (جدول (1). }
$$

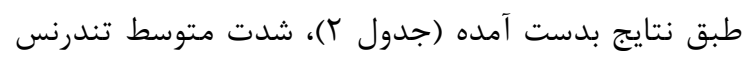

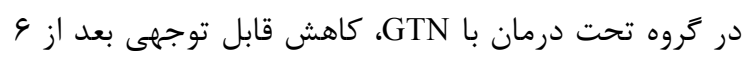

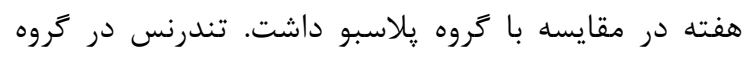

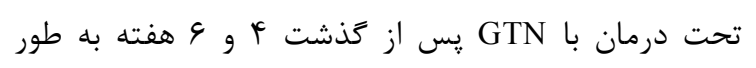

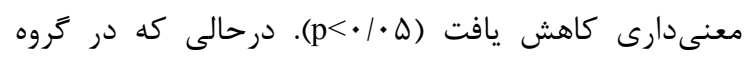

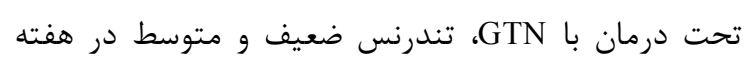

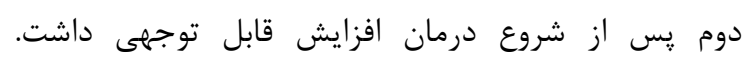

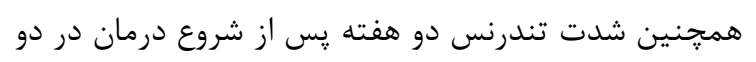

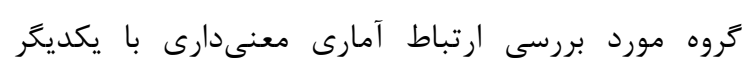

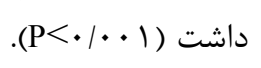

حاوى يارافين (دارونما) تجويز شد. نحوه استفاده و دوز روزانـه دارو

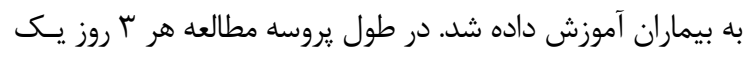

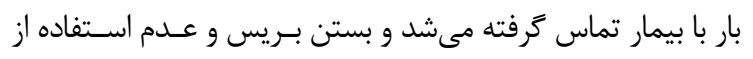

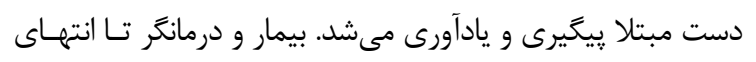

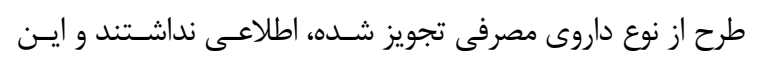

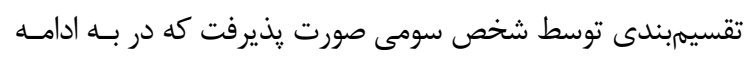

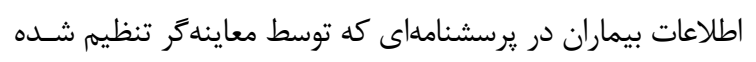

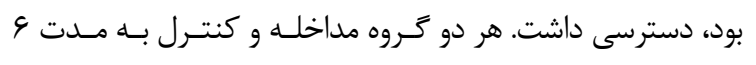

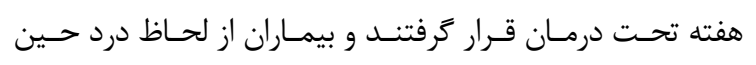
استراحت شبانه، در حين فعاليتهاى روزمـره و تسـت ماوندسـلى فيلى

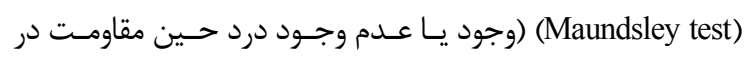

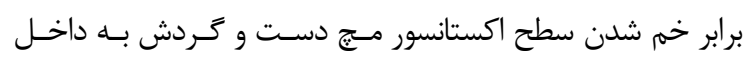

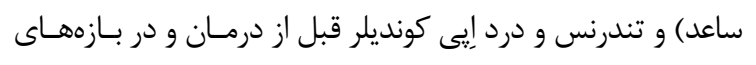
زمانى r، أ و \& هفته يس از شـروع درمـان در دو تـروه بيمـاران

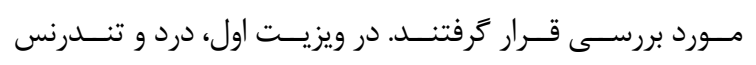

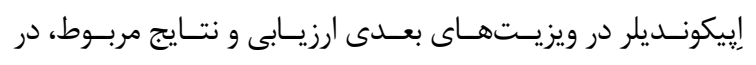

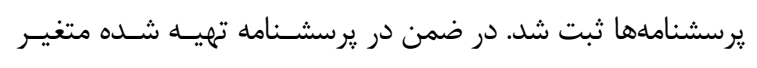

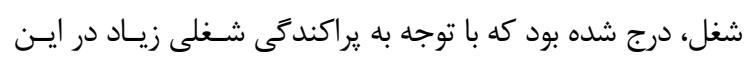

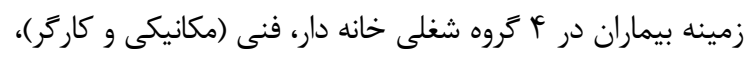
كارمند ادارى و ورزشكار حرفهاى تقسيم بندى شدند.

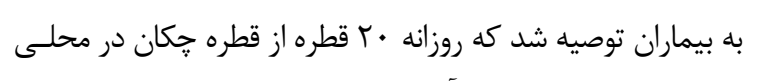

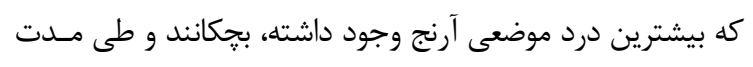

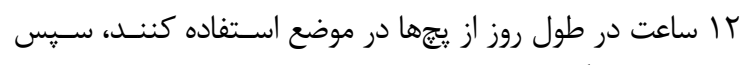

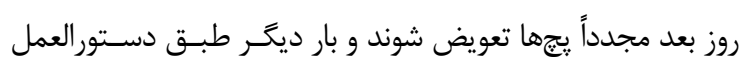

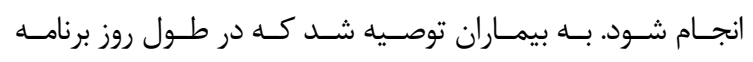

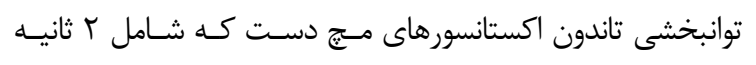

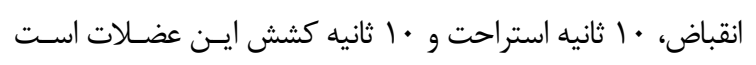

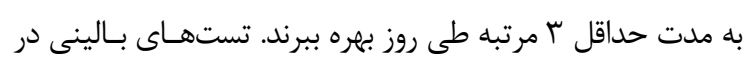

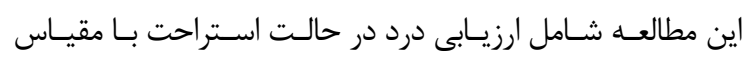
جشمى، درد حين فعاليت با مقياس جشمى، شدت درد درد با مقياس

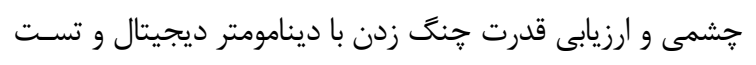

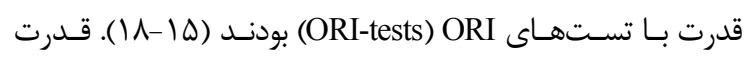

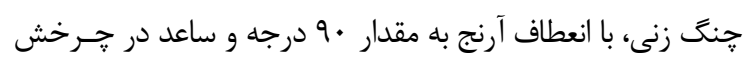

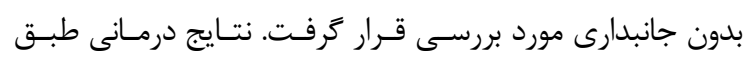

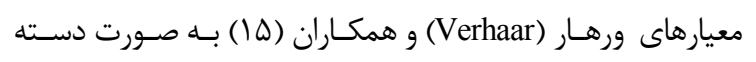
بندى زير تعريف شد؛ "بدون تندريس" (بدون درد، بيمار راضى از هـئ

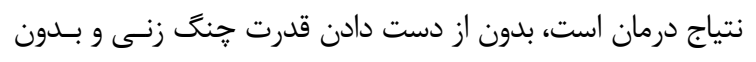

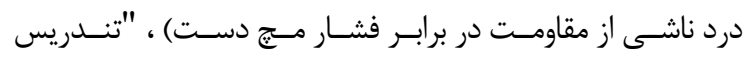
ضعيف" (علائم بطور زشـمخيرى كـاهش يافتـه، بيمـار راضـى از

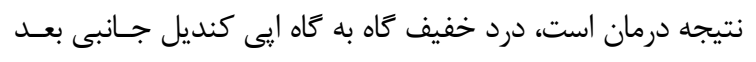


جدول ا. مشخصات دموگرافيك بيماران در زروه مداخله (درمان شده با GTN) و گروه كنترل (درمان شده با دارونما)

\begin{tabular}{|c|c|c|c|}
\hline P-value & كروه كنترل، تحت درمان با دارونما & كروه مداخله، تحت درمان با GTN & \\
\hline \multirow[t]{3}{*}{$\cdot / V 1$} & & r/ • & ميانگَين سن (سال) (ميانكَين لانحراف معيار) \\
\hline & & & شغل (تعداد) \\
\hline & $\wedge$ & 11 & كارمند ادارى \\
\hline \multirow[t]{3}{*}{$\cdot / \Delta T$} & if & 19 & خانهدار \\
\hline & $\checkmark$ & 11 & مكانيكى و كارَرى \\
\hline & $1 \cdot$ & $\checkmark$ & ورزشكار حرفهاى \\
\hline$\cdot / 4 q$ & 每 & Tr/T & جنسيت (مرد/ زن) (تعداد) \\
\hline$\cdot / N \Delta$ & $|\Lambda / r|$ & $r \wedge / \mathrm{V}$ & وضعيت تأهل (مجرد/ متأهل)(تعداد) \\
\hline
\end{tabular}

جدول r. توزيع فراوانى شدت تِندرنس قبل از شروع دوره درمان، و دو، جهار و شش هفته يس از شروع درمان در دو گروه

\begin{tabular}{|c|c|c|c|c|c|c|c|c|}
\hline \multicolumn{2}{|c|}{ 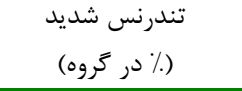 } & \multicolumn{2}{|c|}{ 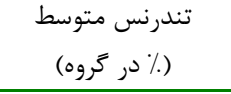 } & \multicolumn{2}{|c|}{ 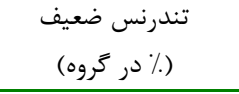 } & \multicolumn{2}{|c|}{ 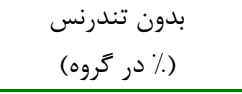 } & \multirow[t]{2}{*}{ دوره زمانى } \\
\hline كنترل & مداخله & 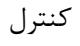 & مداخله & 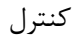 & مداخله & كنترل & مداخله & \\
\hline 10 & IV & $r$. & rA & · & . & . & · & شروع درمان \\
\hline$\checkmark$ & r & ra & rq & it & ir & 1 & • & دو هفته بعد از درمان \\
\hline$\cdot$ & 1 & r & ir & rI & rA & 1 & f & جهار هفته بعد از درمان \\
\hline • & $\cdot$ & 10 & 4 & rA & ir & r & re & ينج هفته بعد از درمان \\
\hline
\end{tabular}

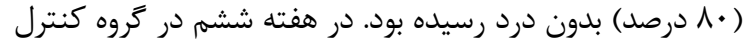

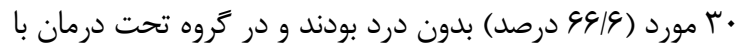
GTN

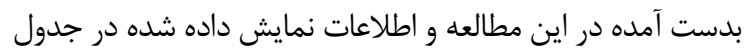

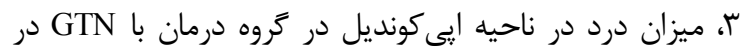

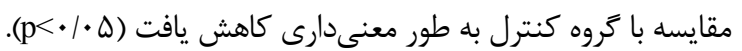

\section{بحث}

در اين بررسى مشخص شد كه تندرنس و درد قبل از درمان در گروه هاى مورد بررسى (تحت درمان با GTN و دارونما) و و

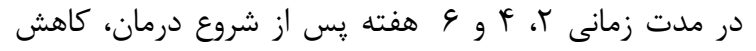
معنى دارى در بيماران زروه مداخله (تحت درمان با GTN) دارد. در يك مطالعه كارآزمايى بالينى دوسوكور تصادفى كه بر دران

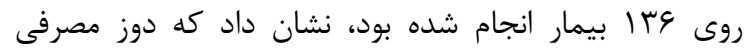

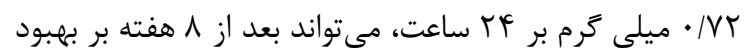

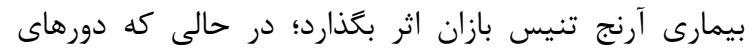

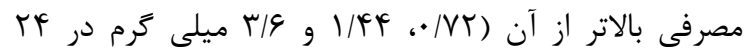

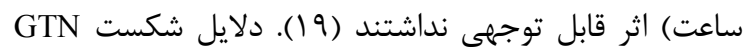
فرموله شده توسط ياولونى نسبت به كارآزمايى قبلى آنها در

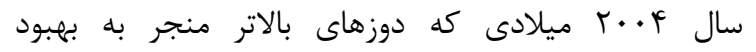

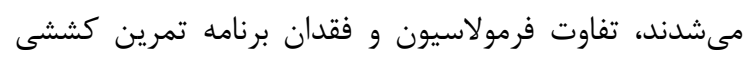

با توجه به جدول با، به طور كلى شدت تندرنس قبل از درمان در گروههاى مورد بررسى (تحت درمان با GTN و

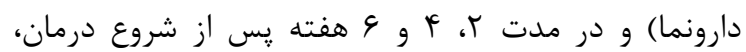
كاهش معنى دارى داشت و اين نتيجه، ميزان تاثير مثبت موضعى GTN, را نشان مى دهد.

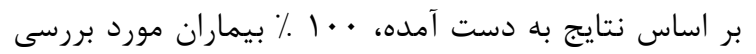
قبل از درمان درد داشتند. در گروه دارونما يس از شروع

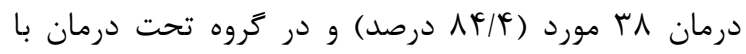
GTN

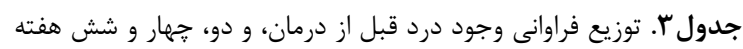

\begin{tabular}{|c|c|c|c|}
\hline \multicolumn{4}{|c|}{ يس از شروع درمان در دو گروه } \\
\hline$P$ value & كروه كنترل & كروه مداخله & \\
\hline- & Fa & $r Q^{*}$ & شروع درمان \\
\hline$<\cdot / \cdot \cdot 1$ & rᄉ & it & دو هفته بعد از درمان \\
\hline$<\cdot 1 \cdot \cdot 1$ & r & 9 & جههار هفته بعد از درمان \\
\hline$\cdot 1 \cdot \cdot 1$ & 10 & 9 & ينج هفته بعد از درمان \\
\hline
\end{tabular}

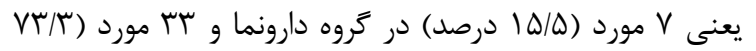
درصد) در زروه مداخله احساس بهبود ميىكردند. در زروه دارونما

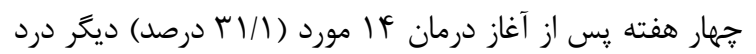

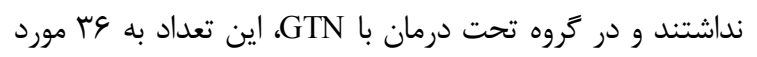


يارامترهاى بيومكانيكى (قدرت بدون درد، سرعت توسعه نيرو)

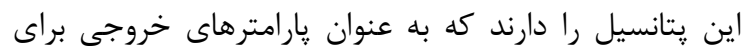

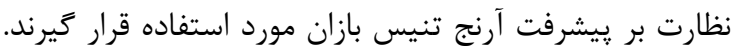

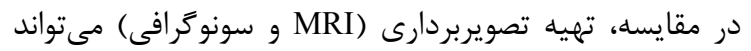

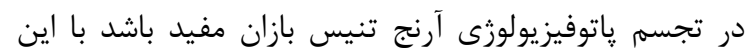

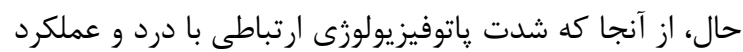

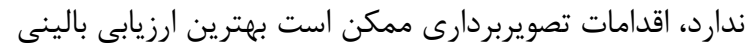

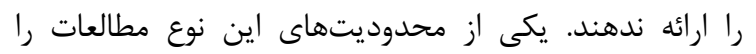
مى توان عدم اطمينان بر انجام تمرينات ورزشى و رعائ رعايت نكات ندات

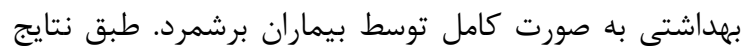

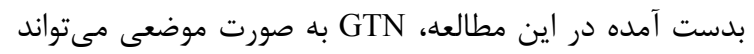
باعث تسريع درمان و بهبود درد و تندرنس در بيماران مبتلا

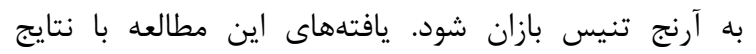
مطالعات مذكور در ديكر مطالعات همخوانى و مشابهت دارد،

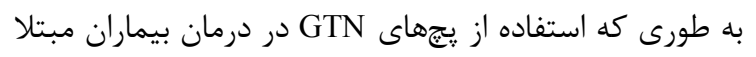

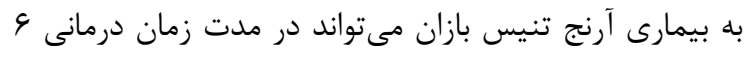

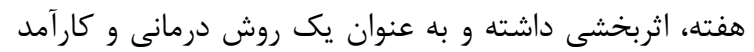

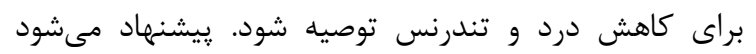

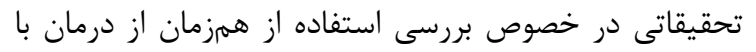
GTN

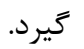

\section{تقدير و تشكر}

بـدين وســله از معاونـت تحقيقــات و فنـآورى دانشـعاه علـوم

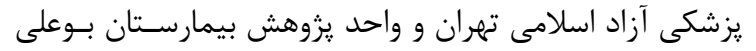

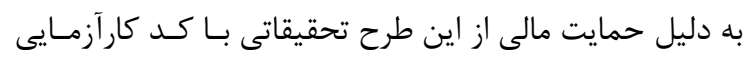

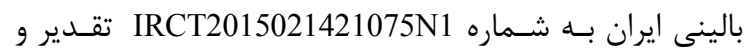

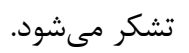

اكستنسور مج دست، به عنوان ضعف اصلى در كنترل بيمارى

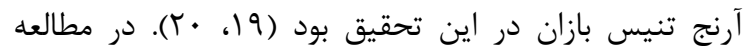

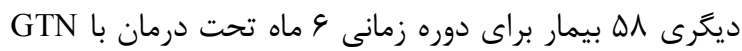

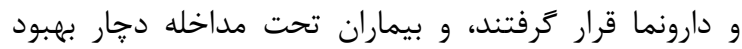

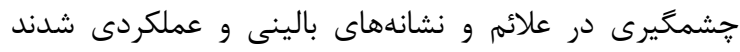

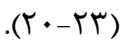
اكسيد نيتريك (NO) يك راديكال آزاد كوجگ است كه توسط خانوادهاى از آنزيمها به نام سنتز اكسيد نيتريك (NOS (NOS) توليد

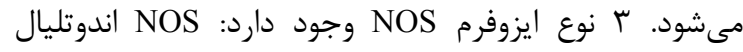

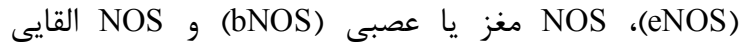
(iNOS)

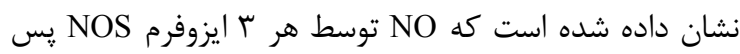

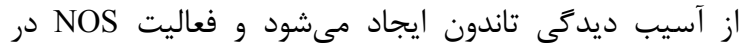

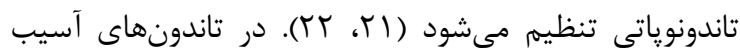

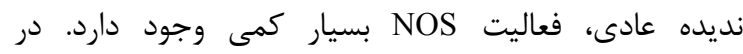

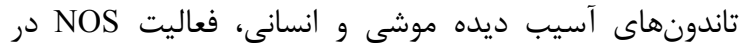

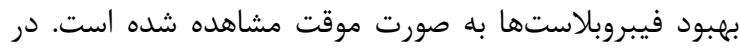

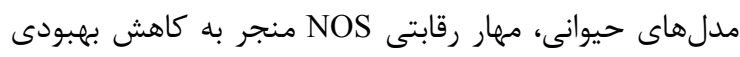

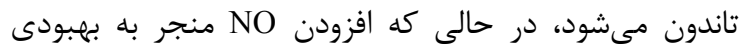

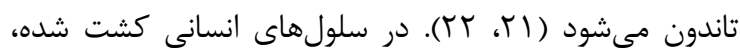

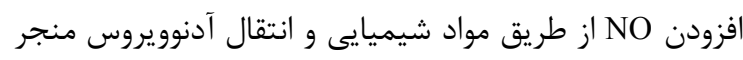

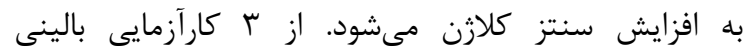
تصادفى، دو سو كور انجام شده، اثر مثبت معنى دار درمانى

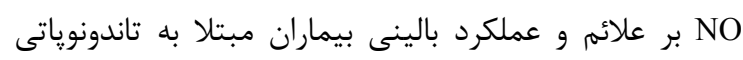

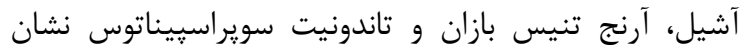

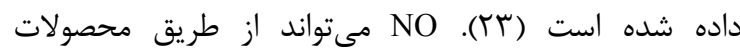

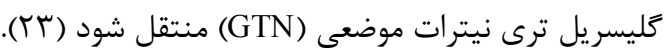

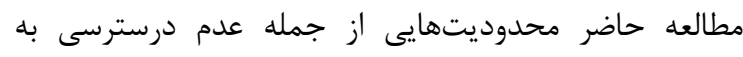

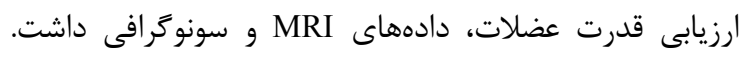

\section{REFERENCES}

1. Khan KM, Cook JL, Bonar F, Harcourt P, Åstrom M. Histopathology of common tendinopathies. Sports Med 1999;27:393-408.

2. du Toit C, Stieler M, Saunders R, Bisset L, Vicenzino B. Diagnostic accuracy of power Doppler ultrasound in patients with chronic tennis elbow. Brit J Sport Med 2008;42:872-6.

3. De Smedt T, de Jong A, Van Leemput W, Lieven D, Van Glabbeek F. Lateral epicondylitis in tennis: update on aetiology, biomechanics and treatment. Brit J Sport Med 2007;41:816-9.

4. Rayan F, Rao VS, Purushothamdas S, Mukundan C, Shafqat SO. Common extensor origin release in recalcitrant lateral epicondylitis-role justified? J Orthop Surg Res 2010;5:31.

5. Haahr JP, Andersen JH. Physical and psychosocial risk factors for lateral epicondylitis: a population based casereferent study. Occup Environ Med 2003;60:322-9.

6. Faro F, Wolf JM. Lateral epicondylitis: review and current concepts. J Hand Surg 2007;32:1271-9. 
7. Walz DM, Newman JS, Konin GP, Ross G. Epicondylitis: pathogenesis, imaging, and treatment. Radiographics 2010;30:167-84.

8. Van CH, Baker JC. Epicondylitis in the athlete's elbow. Clin Sports Med 2010;29:577-97.

9. Murrell GA, Szabo C, Hannafin JA, Jang D, Dolan MM, Deng XH, et al. Modulation of tendon healing by nitric oxide. Inf Res 199746:19-27.

10. Yuan J, Murrell GA, Wei AQ, Appleyard RC, Del Soldato P, Wang MX. Addition of nitric oxide via nitroflurbiprofen enhances the material properties of early healing of young rat Achilles tendons. Inf Res 2003;52:2307.

11. Stasinopoulos D, Stasinopoulou K, Johnson MI. An exercise programme for the management of lateral elbow tendinopathy. Brit J Sport Med 2005;39:944-7.

12. Vuurberg G, Kerkhoffs GM. Topical NSAIDs significantly reduces pain in adults with acute musculoskeletal injuries. BMJ Evidence-Based Med 2016;21:187-8.

13. Bisset L, Beller E, Jull G, Brooks P, Darnell R, Vicenzino B. Mobilisation with movement and exercise, corticosteroid injection, or wait and see for tennis elbow: randomised trial. BMJ 2006;333:939.

14. Xia W, Szomor Z, Wang Y, Murrell GA. Nitric oxide enhances collagen synthesis in cultured human tendon cells. J Orthop Res 2006;24:159-72.

15. Verhaar JA, Walenkamp GH, Kester A. Lateral extensor release for tennis elbow. A prospective long-term followup study. J Bone Joint Surg Am 1993;75:1034-43.

16. Kim J, Lee KS, Kong SW, Kim T, Kim MJ, Park SB, et al. Correlations between electrically quantified pain degree, subjectively assessed visual analogue scale, and the McGill pain questionnaire: a pilot study. Ann Rehabil Med 2014;38:665.

17. España-Romero V, Ortega FB, Vicente-Rodríguez G, Artero EG, Rey JP, Ruiz JR. Elbow position affects handgrip strength in adolescents: validity and reliability of Jamar, DynEx, and TKK dynamometers. J Strength Cond Res 2010;24:272-7.

18. Bohannon RW. Make tests and break tests of elbow flexor muscle strength. Phys Ther 1988;68:193-4.

19. Paoloni JA, Murrell GA, Burch RM, Ang RY. Randomised, double-blind, placebo-controlled clinical trial of a new topical glyceryl trinitrate patch for chronic lateral epicondylosis. Brit J Sport Med 2009;43:299-302.

20. Paoloni JA, Appleyard RC, Murrell GA. The Orthopaedic Research Institute-Tennis Elbow Testing System: a modified chair pick-up test-interrater and intrarater reliability testing and validity for monitoring lateral epicondylosis. J Shoulder Elbow Surg 2004;13:72-7.

21. McCallum SD, Paoloni JA, Murrell GA. Five-year prospective comparison study of topical glyceryl trinitrate treatment of chronic lateral epicondylosis at the elbow. Brit J Sport Med 2011;45:416-20.

22. Murrell GA, Szabo C, Hannafin JA, Jang D, Dolan MM, Deng XH, et al. Modulation of tendon healing by nitric oxide. Inf Res 1997;46:19-27.

23. Bokhari AR, Murrell GA. The role of nitric oxide in tendon healing. J Shoulder Elbow Surg. 2012;21:238-44. 